\title{
Absence of color selectivity in the visual movement aftereffect
}

\author{
R. H. DAY \\ Monash University, Clayton, Victoria 3168, Australia \\ and \\ N. J. WADE \\ University of Dundee, Dundee DDI $4 H N$, Scotland
}

\begin{abstract}
Lovegrove, Over, and Broerse (1972) reported that the magnitude of the movement aftereffect was reduced when the colors of the inducing and test stimuli differed, relative to when they were the same. Since this result is contrary to some earlier findings, four experiments were conducted to examine this claim. Neither the duration nor the magnitude (as measured by manual tracking) of the aftereffect generated by rotary or linear movement of contours were found to be affected by the color combinations of the inducing and stationary patterns.
\end{abstract}

Prolonged observation of regularly moving contours leads to the apparent movement of the same contours in the reverse direction when they are rendered stationary. This movement aftereffect was initially described by Aristotle (Beare, 1931, p. 459b) after viewing fast flowing water in rivers, although its direction was not specified (see also Müller, 1842 , p. 1180), and it has also been observed after exposure to such diverse situations as extended cavalry parades (Purkinje, 1825) and waterfalls (Addams, 1834). More recently, its extensive study has been confined largely to controlled linear or rotary motion of clearly defined contours.

The aftereffect was first considered to be due to eye movements (Addams, 1834; Purkinje, 1825, pp. 60-62) or the successive fading of afterimages (Müller, 1842), but both of these hypotheses have been found to be inadequate (see Wohlgemuth, 1911). Currently, it is thought that the basis of the aftereffect might lie within the visual system, most probably at the level of the visual cortex. Some cortical cells respond more strongly to stimulus movement in one direction than in the reverse, and adapting those cells sensitive to a particular direction would bias the distribution of cells responding to stationary contours (Barlow \& Hill, 1963; Sutherland, 1961).

This view has been extended by Lovegrove, Over, and Broerse (1972). They have suggested that the movement analyzers are also color selective, as they

\footnotetext{
This research was supported by grants from the Medical Research Council to N.J.W. and from the Australian Research Grants Committee to R.H.D. The first two experiments were conducted at Dundee University and the last two at Monash University. The assistance of Linda Wilson and Jane Millar in the collection of the data is gratefully acknowledged.
}

found that the magnitude of the movement aftereffect was influenced by the color of the moving inspection and stationary tests contours: the aftereffect was smaller if the colors during the two phases differed compared with the conditions in which they were the same. Lovegrove et al. took as their starting point the results from a movement aftereffect generated by a rather different procedure first described by Hepler (1968). Hepler presented subjects with upward-moving green (or red) bars alternating every $5 \mathrm{sec}$ with downward-moving red (or green) bars, and this sequence lasted for about $30 \mathrm{~min}$. Subsequently, black and white moving bars appeared in the color complementary to that presented during inspection. It has also been found that a stationary pattern can appear to move in a direction contingent upon its color following similar stimulus alternation (Favreau, Emerson, \& Corballis, 1972). Unlike the classical movement aftereffect described initially, these latter require alternation of movement in two directions for their occurrence (Stromeyer \& Mansfield, 1970).

The report by Lovegrove et al. of color contingency for the classical movement aftereffect is at variance with one of Wohlgemuth's (1911) many experiments (Experiment 29), and also with one carried out in the context of rod-cone interaction (Anstis, 1964). Anstis examined the aftereffect produced by a rotating sectored disk when illuminated through the same or different blue and red filters; the durations of the aftereffects were not influenced by the color of the moving and stationary patterns.

In order to investigate this discrepancy between these independent reports, a preliminary experiment was conducted with a rotating disk, like that used by Anstis, viewed monocularly through red or 
green filters and tested when stationary with the same or with a different color. (The experimental conditions and procedure were similar to those of Experiment 1 below.) Thirty-two subjects were tested in each of four conditions; they fixated the center of a disk rotating at $36^{\circ} / \mathrm{sec}$ for $30 \mathrm{sec}$ and then indicated verbally when the apparent rotation of the stationary disk ceased. The average durations for the aftereffect with the following inspection and test colors were: red-red, $15.3 \mathrm{sec}$; red-green, $15.0 \mathrm{sec}$; green-red, $15.8 \mathrm{sec}$; green-green, $15.5 \mathrm{sec}$. There were no significant differences between the four conditions, and the results clearly support those of Anstis (1964).

However, Lovegrove et al. did not measure the duration of the aftereffect, but gave an index of the magnitude of apparent movement within a 15 -sec interval following the inspection or induction period, using a manual tracking method (see Day \& Strelow, 1971). While it would be surprising if the two measures of the aftereffect were not closely related, we conducted three experiments using manual tracking methods in order to obtain a more direct comparison with the experiment by Lovegrove et al. The first experiment involved rotary motion, and the other two linear motion.

\section{EXPERIMENT 1}

\section{Method}

Subjects. Twenty subjects with normal or corrected-to-normal vision were tested in the experiment.

Apparatus. The movement aftereffect was induced by inspection of a 32-black-and-white-sectored disk, which was viewed from a distance of $145 \mathrm{~cm}$ and subtended $8^{\circ}$ at the eye. The disk was mounted in front of a white background and surrounded by a stationary black outline square, subtending $12^{\circ}$ on each side. This outline square, which was visible continuously, enhanced the visibility of the aftereffect (see Day \& Strelow, 1971; Grindley, 1930). The disk could be viewed through one of two laterally placed apertures, behind which filters could be inserted. The color filters used were Kodak Wratten Nos. 29 and 61. Wratten No. 29 is a deep red, narrow-cut filter with a sharp cutoff at about $600 \mathrm{~nm}$ with no transmission of shorter wavelength light. Wratten No. 61 is a deep green, narrow-cut filter with a peak transmission of about $530 \mathrm{~nm}$. At $10 \%$ transmission, the range was about $500-570 \mathrm{~nm}$. Less than $1 \%$ of the transmitted light was $600 \mathrm{~nm}$ or greater. Thus there was virtually no overlap between the wavelengths of the two filters.' It should be noted that the filters used by Lovegrove, Over, and Broerse were Wratten Nos. 33 and 61 .

Mounted beneath and on the right side of the table at which the subject sat was a disk that could be rotated using a handle. The extent of the subject's rotation of this disk was recorded by means of photoelectric cells and an electronic counter.

Procedure. The subject viewed the disk, rotating at $36 \% \mathrm{sec}$, for $30 \mathrm{sec}$, whereupon it was stopped almost instantaneously. The subject used the right eye only, and viewed the moving disk through one aperture, then, after a warning signal from the experimenter, moved the head to the right by about $7 \mathrm{~cm}$ to observe the stationary disk. The filters behind the apertures were either both the same or of different colors, making four combinations in all. The subject's task was to rotate the handle of the tracking disk to match the apparent velocity of the stationary pattern for $15 \mathrm{sec}$. Subjects were given two practice trials before commencement of the experimental series, and each color combination was tested once. A rest of 3 min was given between trials, and their order of presentation was randomized.

\section{Results}

The extent of rotation (in degrees) of the tracking disk during $15 \mathrm{sec}$ was taken as the measure of the movement aftereffect. The means and standard errors for the four color combinations are given in Table 1. It is clear that there was little difference in the degree of apparent rotation under the different conditions, and this was supported statistically $(\mathrm{F}=0.33, \mathrm{df}=$ $3,57, p>.05$ ). Hence, these results are in agreement with those of the preliminary experiment and of Anstis (1964) in demonstrating that the magnitude of the movement aftereffect with a rotating pattern is not influenced by the color characteristics of the inspection and test stimuli.

\section{EXPERIMENT 2}

In this experiment, the movement aftereffect was induced by laterally moving contours.

\section{Method}

Subjects. Twelve subjects, all of whom were graduate or undergraduate students, took part in the experiment.

Apparatus. The stimulus arrangement consisted of a box with two circular apertures, each of $5 \mathrm{~cm}$ diameter, one above the other and separated by $20 \mathrm{~cm}$ between centers. The upper aperture was used for inducing the movement aftereffect and the lower one for testing it. The box was $42 \times 42 \times 40 \mathrm{~cm}$, and the front was patterned with vertical black and white bars $2 \mathrm{~cm}$ wide. The vertical black and white bars which appeared in the aperture were also $2 \mathrm{~cm}$ wide, so that 1.25 cycles of the grating were visible. The grating in the upper aperture moved from left to right at $2.5 \mathrm{cycles} / \mathrm{sec}$. The colors of the two apertures could be varied by means of red or green filters (Kodak Wratten No. 33 and No. 61, respectively, as used by Lovegrove et al., 1972) in front of the apertures. Number 61 has already been described. Number 33 is a deep red filter which has a sharp cutoff at about $620 \mathrm{~nm}$, with transmission above this wavelength nearly $100 \%$. There is some transmission of shorter wavelengths peaking at about 470 and $380 \mathrm{~nm}$, but neither exceeds about $15 \%$. Even allowing for these short wavelength components, there is virtually no overlap between the wavelengths transmitted by the red and green filters. The luminance of the two apertures, matched by eye, was about $15 \mathrm{~cd} / \mathrm{m}^{2}$. A small white fixation point was placed on each filter so that it was centered in the circular aperture.

The subject's head was supported by a chinrest, and the pattern was viewed from $167 \mathrm{~cm}$, so that the aperture subtended $1.7^{\circ}$ and the grating had a spatial frequency of 1.1 cycles/deg. A

Table 1

Means (in Degrees) and Standard Errors (SE) for the Amount of Tracked Rotation (Taken as a Measure of the Movement Aftereffect Magnitude) During 15 sec After Viewing the Rotating Disk

\begin{tabular}{lcccc}
\hline Inspection Color & Red & Red & Green & Green \\
Test Color & Red & Green & Red & Green \\
Mean & 36.9 & 36.8 & 36.0 & 34.0 \\
SE & 3.1 & 3.1 & 3.1 & 2.9 \\
\hline
\end{tabular}


Table 2

Means (in Millimeters) and Standard Errors (SE) for the Magnitude of the Movement Aftereffect During $15 \mathrm{sec}$ Following Inspection of Laterally Moving Bars (Experiment 2)

\begin{tabular}{lcccc}
\hline Inspection Color & Red & Red & Green & Green \\
Test Color & Red & Green & Red & Green \\
Mean & 32.8 & 36.3 & 35.4 & 35.5 \\
SE & 5.7 & 8.1 & 8.7 & 8.9 \\
\hline
\end{tabular}

manual tracking device was positioned by the subject's right hand. The subject was required to move a carriage laterally at the same apparent speed as the aftereffect (see Day \& Strelow, 1971, for further details).

Procedure. The movement aftereffect was induced by a 2 -min binocular fixation of the dot in front of the moving bars, and tracked manually during $15 \mathrm{sec}$ binocular fixation upon the point in front of the stationary bars. Each subject was given a practice trial before commencement of the four experimental trials, which involved red-red, red-green, green-green, and green-red combinations for inducing and test phases. The orders of these four trials were different for each subject.

\section{Results}

The magnitude of the movement aftereffect was derived in the same manner as for the experiment by Lovegrove et al., namely, the distance in millimeters of lateral pen movement throughout the $15-\mathrm{sec}$ test period. The means and standard errors are given in Table 2 for all four conditions. The values for the red-red and green-green conditions are commensurate with those quoted by Lovegrove et al., but there was no diminution of the aftereffect when the colors were different. Analyzing the data in the same way as Lovegrove et al., there were no significant effects for inspection color, test color, or for the interaction between them $(F=.07, .54$, and .40 , respectively; $\mathrm{df}=1,11, \mathrm{p}>.05$, in all cases) on the magnitude of the movement aftereffect.

\section{EXPERIMENT 3}

This third failure to obtain results like those reported by Lovegrove et al. led to one final attempt, under conditions that were as similar to theirs as we could make them. The apparatus used in the previous experiment was modeled on theirs, but slightly different induction procedures were employed. Lovegrove et al. gave subjects an initial 4-min inspection of the moving target, and measured the pen displacement for the following $15 \mathrm{sec}$, whereupon the aftereffect was regenerated with a further 1-min inspection; this procedure was repeated until four aftereffect measures were derived for each color combination. Moreover, the subjects were tested monocularly.

\section{Method}

Subjects. Eight subjects were tested, two of whom had participated in Experiment 2.

Apparatus. The apparatus was exactly the same as that used in Experiment 2.
Procedure. The procedure was similar to that employed by Lovegrove et al. in all essentials. Four color combinations were examined. In each condition, four aftereffect measurements were derived, the first following 4-min inspection and the other three after 1-min inspection periods. The subject tracked the apparent movement for $15 \mathrm{sec}$ following each inspection period. Two conditions were run on one day and the other two on the next, with a different random order for each subject. The rest interval between the two conditions on a given day was $5 \mathrm{~min}$. The subject used the right eye throughout, and the left eye was occluded.

\section{Results}

The magnitude of the movement aftereffect was taken as the amount of lateral pen movement in the 15-sec test period. The means and standard errors are given in Table 3. The values for the aftereffect are slightly longer than those of Experiment 2, probably as a consequence of the longer initial inspection. However, the results are consonant with those of the previous experiment, as neither the inspection color, the test color, nor the interaction between them reached statistical significance $(F=$ $1.41,3.01, .35$, respectively; $\mathrm{df}=1,7, \mathrm{p}>.05$ in all cases).

\section{DISCUSSION}

The effect of color on the movement aftereffect has been examined in several ways. There is general agreement that the duration of the aftereffect is not affected by the color of the inducing and test patterns if these are both the same, and if the colors are equal in brightness (Anstis, 1964; Grindley, 1930; Wohlgemuth, 1911). However, Lovegrove et al. have reported data to suggest that the magnitude of the aftereffect is reduced when the stationary pattern is of a different color to the moving pattern. These data are contrary to those of Anstis (1964) and Wohlgemuth (1911). We have conducted four experiments which provide strong support for the latter: neither the duration nor the magnitude (as measured by the manual tracking method) of the movement aftereffect were affected by the color of the inducing and test stimuli for either rotary or linear movement. The reason for the solitary discrepancy of Lovegrove et al. remains obscure, but the weight of evidence would clearly favor the earlier conclusions reached by Wohlgemuth and Anstis. Moreover, the proposals by Lovegrove et al. that the monocular movement detectors are tuned to wavelength cannot be sustained

Table 3

\begin{tabular}{|c|c|c|c|c|}
\hline \multicolumn{5}{|c|}{$\begin{array}{l}\text { Means (in Millimeters) and Standard Errors (SE) for the } \\
\text { Magnitude of the Movement Aftereffect During } 15 \text { sec } \\
\text { Following Inspection of Laterally Moving Bars } \\
\text { (Experiment 3) }\end{array}$} \\
\hline $\begin{array}{l}\text { Color } \\
\text { Color }\end{array}$ & $\begin{array}{r}\text { Red } \\
\text { Red } \\
37.8 \\
8.3\end{array}$ & $\begin{array}{l}\text { Red } \\
\text { Green } \\
42.3 \\
8.9\end{array}$ & $\begin{array}{l}\text { Green } \\
\text { Red } \\
39.9 \\
9.6\end{array}$ & $\begin{array}{l}\text { Green } \\
\text { Green } \\
47.8 \\
12.7\end{array}$ \\
\hline
\end{tabular}


on the present evidence from classical movement aftereffects. Indeed, the lack of color selectivity in the classical movement aftereffect provides a further distinction between them and the color-contingent aftereffects of the McCullough variety.

\section{REFERENCES}

AdDams, R. An account of a peculiar optical phaenomenon after having looked at a moving body. London and Edinburgh Philosophical Magazine and Journal of Science, 1834, 5, 373-374.

Anstis, S. M. After-effect of seen motion: Transfer from rods to cones and vice versa. Nature, 1964, 201, 952.

Barlow, H. B., \& Hill, R. M. Evidence for a physiological explanation of the waterfall phenomenon and figural after-effects. Nature, 1963, 200, 1345-1347.

Beare, J. I. Parva Naturalia. De Somniis. In W. D. Ross (Ed.), The works of Aristotle translated into English (Vol. III). Oxford: University Press, 1931.

DAY, R. H., \& Strelow, E. R. Visual aftereffect of movement: Partial or complete reduction in the absence of a patterned surround. Nature, 1971, 230, 55-56.

Favreau, O., Emerson, V., \& Corballis, M. Motion perception: A color-contingent aftereffect. Science, 1972, 176, 78-79.

Grindley, G. C. The relation between the rod and cone mechanisms in the aftereffect of seen movement. Journal of Physiology. 1930, 69, 53-59.
HEPLER, N. Color: A motion-contingent aftereffect. Science, 1968, 162, 376-377.

LOVEGROVE, W. J., OVER, R., \& Broerse, J. Colour selectivity in motion after-effect. Nature, 1972, 238, 334-335.

MULleR, J. Elements of physiology (Vol. II) (Translated by W. Baly). London: Taylor and Walton, 1842.

Purkinje, J. Beobachtungen und Versuche zur Physiologie der Sinne. Neue Beiträge zur Kenntniss des Sehens in subjectiver Hinsicht (Zeites Bändchen). Berlin: Reimer, 1825.

Stromeyer, C. F., \& Mansfield, R. Colored aftereffects produced with moving edges. Perception \& Psychophysics, 1970, $7,108-114$

SutHerLand, N. S. Figural after-effects and apparent size. Quarterly Journal of Experimental Psychology, 1961, 13, 222-228.

WoHlgemuth, A. On the after-effect of seen movement. British Journal of Psychology Monograph Supplement, 1911, 1, 1-117.

\section{NOTE}

1. Details of Kodak Wratten filter transmissions were obtained from a recent Kodak catalogue, The Kodak Range of Light Filters (undated), printed in England and indexed as K3281PD285/ axRL3/10-72.

(Received for publication December 15, 1978; revision accepted May 5, 1978.) 